\title{
BMJ Open Identifying and delineating the type 2 diabetes population in the Netherlands using an all-payer claims database: characteristics, healthcare utilisation and expenditures
}

Rose J Geurten (D) , ${ }^{1}$ Arianne M J Elissen (D) , ${ }^{1}$ Henk J G Bilo, ${ }^{2}$ Jeroen N Struijs, ${ }^{3,4}$ Chantal van Tilburg, ${ }^{5}$ Dirk Ruwaard ${ }^{1}$

To cite: Geurten RJ,

Elissen AMJ, Bilo HJG, et al. Identifying and delineating the type 2 diabetes population in the Netherlands using an all-payer claims database: characteristics, healthcare utilisation and expenditures. BMJ Open 2021;11:e049487. doi:10.1136/ bmjopen-2021-049487

- Prepublication history and additional supplemental material for this paper are available online. To view these files, please visit the journal online (http://dx.doi.org/10.1136/ bmjopen-2021-049487)

Received 26 January 2021 Accepted 17 November 2021

\section{Check for updates}

(c) Author(s) (or their employer(s)) 2021. Re-use permitted under CC BY-NC. No commercial re-use. See rights and permissions. Published by BMJ.

For numbered affiliations see end of article.

\section{Correspondence to}

Rose J Geurten;

r.geurten@maastrichtuniversity. $\mathrm{nl}$

\section{ABSTRACT}

Objectives We aimed to identify and delineate the Dutch type 2 diabetes population and the distribution of healthcare utilisation and expenditures across the health system from 2016 to 2018 using an all-payer claims database.

Design Retrospective observational cohort study based on an all-payer claims database of the Dutch population. Setting The Netherlands.

Participants The whole Dutch type 2 diabetes population ( $n=900522$ in 2018), determined based on bundled payment codes for integrated diabetes care and medication use indicating type 2 diabetes.

Outcome measures Annual prevalence of type 2 diabetes, comorbidities and characteristics of the type 2 diabetes population, as well as the distribution of healthcare utilisation and expenditures were analysed descriptively.

Results In 2018, 900522 people (6.5\% of adults) were identified as having type 2 diabetes. The most common comorbidity in the population was heart disease (12.1\%). Additionally, $16.2 \%$ and $5.6 \%$ of patients received specialised care for microvascular and macrovascular diabetes-related complications, respectively. Most patients with type 2 diabetes received pharmaceutical care (99.1\%), medical specialist care (97.0\%) and general practitioner consultations $(90.5 \%)$. In total, $€ 8173$ million, $9.4 \%$ of total healthcare expenditures, was reimbursed for the type 2 diabetes population. Medical specialist care accounted for the largest share of spending (38.1\%), followed by district nursing (12.4\%), and pharmaceutical care $(11.5 \%)$.

Conclusions All-payer claims databases can be used to delineate healthcare use: this insight can inform health policy and practice and, thereby, support better decisions to promote long-term sustainability of healthcare systems. The healthcare utilisation of the Dutch type 2 diabetes population is distributed across the health system and utilisation of medical specialist care is high. This is likely to be due to presence of concurrent morbidities and complications. Therefore, a shift from a disease-specific approach to a person-centred and integrated care approach could be beneficial in the treatment of type 2 diabetes.

\section{Strengths and limitations of this study}

- The use of an all-payer claims database enables an overview of the complete Dutch type 2 diabetes population.

- Due to the economic function of claims data, the data are accurate and complete enabling a reliable estimation of healthcare utilisation and expenditures.

- Internationally, the generalisability of findings could be limited because of the differences in the organisation of healthcare.

- Real-time or near-time data use of claims data are hampered by a 2-year time lag.

\section{INTRODUCTION}

Internationally, there are rising concerns regarding the financial sustainability of healthcare systems. This financial strain is caused by increasing costs associated with ageing populations, rising life expectancy, expensive technological advances and higher patient expectations. ${ }^{1-3}$ In particular, the burden caused by chronic diseases is rapidly increasing. ${ }^{4}$ Diabetes mellitus is currently one of the most prevalent chronic diseases affecting an estimated 463 million people in the age group 20-79 years, or $9.3 \%$ of adults worldwide. ${ }^{45}$ This number is expected to rise to 700 million by $2045 .^{5}$ Within the diabetes population, $90 \%$ of patients suffer from type 2 diabetes. ${ }^{56}$ Many develop at least one diabetes-related macrovascular or microvascular complication during the course of their disease. ${ }^{78}$ The presence of these complications substantially increases healthcare utilisation and expenditures. $^{7-12}$ For instance, the presence of both microvascular and macrovascular complications increases patients' care expenditures by up to $250 \% .^{7}$ In total, 
expenditures on diabetes-related complications are estimated to amount to more than half of all diabetes care expenditures. $^{1314}$

However, to date, knowledge on healthcare utilisation and expenditures of nationwide type 2 diabetes populations remains limited as national diabetes registries are rare and studies on diabetes care costs are often based on data from smaller subgroups of patients. These subgroups are generally based on patients with diabetes who suffered a specific event, geographically defined groups, insurance defined groups, patients of specific care organisations or random samples. ${ }^{9-11}{ }^{15-21}$ Thus, the use of data representing a heterogeneous, nationwide type 2 diabetes populations is rare, ${ }^{16}$ and therefore the generalisability of prior research findings is limited. Additionally, prior studies are often based on self-reported cost data which may lead to recall bias. ${ }^{891215}$ Existing insights into expenditures on type 2 diabetes-related complications are similarly fragmented and unclear. ${ }^{11} 1415$ This is caused by the limited number of papers covering this topic, difficulties in separating diabetes-related expenditures, as well as poor transparency regarding cost sources in existing studies. ${ }^{11}{ }^{22}$ In addition, previous studies in this area have often focused on hospital care or analysed only one specific diabetes-related complication. ${ }^{8}$ Accordingly, estimates of expenditures on complications vary widely. ${ }^{22}$

Because of the increasing concerns about the financial sustainability of healthcare systems and the rising prevalence of type 2 diabetes, a more exact insight into the healthcare utilisation and expenditures of type 2 diabetes populations is needed. The current focus on specific subgroups limits available evidence on heterogeneity of healthcare utilisation and costs in whole diabetes populations. Such insight would enhance understanding of where and how much diabetes care is provided, support better decisions to promote long-term sustainability and aid tailoring policies and practice to achieve improvements on the Quadruple Aim. ${ }^{23}$ Therefore, we use an all-payer claims database (APCD) that covers $99 \%$ of the Dutch population to identify the Dutch type 2 diabetes population and present a detailed and complete overview of population characteristics, healthcare utilisation and expenditures. APCDs are becoming increasingly important in facing healthcare challenges as these enable analysis of whole populations across the health system, as well as over time. ${ }^{24-26}$ Accordingly, the aim of this study is twofold. The first aim is to specify the size and characteristics of the Dutch type 2 diabetes population, including the annual prevalence of chronic comorbidities and type 2 diabetes-related complications, over the years 20162018. The second aim is to determine the total healthcare utilisation and expenditures of this population and the distribution of use and expenditures (a) across healthcare sectors (eg, primary care, specialised care); (b) related to specific service types (eg, mental healthcare, pharmaceutical care) and; (c) for type 2 diabetes-related complications (eg, heart failure, diabetic foot) over the same time period.

\section{METHODS}

\section{Data source}

This retrospective observational study was based on an APCD from the national health insurance registry managed by the Vektis Healthcare Information Center. Vektis was set up by Dutch health insurers in 2006 to support claims reimbursement, provide high quality, accurate and complete data for Dutch risk equalisation model and enable the main players in the Dutch healthcare market to base their decision-making and policy execution on reliable, essential and timely data. ${ }^{27}$ For this purpose, the Vektis databases contain information on all procedures covered by Dutch statutory health insurance, as well as a set of data on patients, providers, care products and prices. Before integration into the Vektis databases, health insurers' data undergo rigorous inspection and validation. Vektis' coverage rate has gradually expanded since 2006: the information centre now receives data from all Dutch health insurers and covers over $99 \%$ of the Dutch population. For this study, comprehensive claims data on the type 2 diabetes population spanning across healthcare sectors and service types for the timeframe 2016-2018 were drawn from the Vektis registry. The timeframe 2016-2018 was chosen to examine most recent data and because no major policy changes regarding diabetes care were made during this period.

\section{Study population}

In the Netherlands, the vast majority of patients with type 2 diabetes (83\% in 2018) receive integrated diabetes care within a primary care setting organised by care groups, ${ }^{28}$ that is, regionally organised healthcare provider groups comprising general practitioners (GPs) and affiliated personnel. These integrated diabetes care programmes are funded by health insurers on the basis of a bundled payment per patient per year. ${ }^{29}$ We used existing bundled payment claim codes to identify patients with type 2 diabetes in the APCD. Most of the remaining 17\% of Dutch patients with type 2 diabetes are treated in secondary care, by a medical specialist, due to the complexity of their condition. Complex diabetes cases include patients who cannot reach glycaemic control in primary care or patients who need a more intricate treatment for complications or risk factors (eg, treatment resistant cardiovascular risk factors) under management of a medical specialist. ${ }^{30}$ In addition, a small group of patients is treated in primary care by a GP who is not affiliated with a care group and, as such, are not covered by the bundled payment system. To identify these remaining patients with type 2 diabetes, we assessed medication use (based on Anatomical Therapeutic Chemical (ATC) codes) indicating type 2 diabetes. Identification based on medication use is possible in the Netherlands due to the relatively strict and stepwise medication guideline for type 2 diabetes management. ${ }^{31}$ Thus, to be as accurate and inclusive as possible, we identified individuals as patients with type 2 diabetes if they met one or more of the following criteria: (a) received integrated diabetes care or (b) were treated for their type 2 diabetes with (b.1.) 
only oral medication (A10B blood glucose lowering drugs excluding insulins); (b.2.) a combination of insulin (A10A insulins and analogues for injection) and oral medication (A10B blood glucose lowering drugs excluding insulins), or (b.3.) a combination medication (A10AE54 or A10AE56: mix of insulins and GLP-1 for injection, long-acting). Individuals were included based on medication use if they received any of the medications described at least once in that year. We determined the type 2 diabetes population separately for each year within the timeframe 2016-2018. Individuals were included in the annual population prevalence if one or more of the inclusion criteria applied at any time during that year. Accordingly, the study population had the nature of an open and dynamic cohort, to which individuals could be added or excluded from each year. No exclusion criteria were applied.

\section{Patient and population characteristics}

To describe the study population, we included age, gender and presence of chronic comorbidities and type 2 diabetes complications. The presence of chronic comorbidities was assessed by 'pharmaceutical costs groups' (In Dutch: Farmaceutische KostenGroepen, FKGs) which are used for the Dutch risk equalisation scheme for health insurers. ${ }^{32}$ FKGs are a proven tool to identify insured persons with chronic conditions, such as glaucoma or heart disease, by means of medication claims. ${ }^{33}$ An FKG is ascribed to an insured person when he/she is issued prescriptions for more than a certain dose of medication (ie, enough for approximately 6 months' use) in a given year.

Presence of type 2 diabetes-related complications was assessed per year based on 'diagnosis-treatment combinations' (in Dutch: diagnose-behandelcombinaties, DBCs). In the Netherlands, specialised care is reimbursed via DBCs, a concept similar to diagnosis-related groups. DBCs consider complete episodes of care for a specific diagnosis, thus DBCs contain information on specialism or responsible specialised physician, patient diagnosis and provided treatment. ${ }^{34}$ Moreover, one DBC may contain a number of healthcare consultations, tests or treatments. For one DBC, health insurers reimburse the average expenditures made for the related diagnosis. One of the authors, who is an internist (HJGB), matched the associated DBCs to the type 2 diabetes-related complications (online supplemental table 1). We focused on the most common complications listed by Nathanson et al..$^{35}$ For macrovascular complications, these were acute coronary syndrome, stroke and heart failure. Microvascular complications included diabetic mononeuropathy/polyneuropathy, diabetic eye complications, diabetic foot/peripheral angiopathy and diabetic kidney disease. If a relevant DBC was reimbursed once in a given year, that patient was registered as having the associated type 2 diabetes-related complication.

\section{Healthcare utilisation and expenditures}

This study considered total healthcare expenditures of the type 2 diabetes population under the Dutch Health
Insurance Act (In Dutch: Zorgverzekeringswet), as well as under the Long-term Care Act (In Dutch: Wet Langdurige Zorg). Together, these two acts account for the bulk of the available healthcare budget in the Netherlands. For the Dutch Health Insurance Act, utilisation and expenditures of the type 2 diabetes population related to a number of healthcare sectors and service types were extracted from the Vektis databases. Data on the primary care and specialised care (care provided in hospitals and independent specialised treatment centres) sectors were studied in detail. Utilisation of primary care covered patients registered with a GP, whereas utilisation of GP consultations included patients that used regular consultations (excluding integrated diabetes care consultations), home visits and consultations via email and by phone. Moreover, we distinguished data regarding service types: pharmaceutical care, assistive devices, mental healthcare, district nursing, paramedical care and other care. Other care included maternity care, obstetrics, oral care, patient transport, care abroad, geriatric rehabilitation, primary care support and inpatient primary care. Expenditures within these specified healthcare sectors and services were also considered at the individual patient level. Utilisation and expenditures both directly related to diabetes care as well as other (non-diabetes related) services were included. The expenditures considered under the Dutch Health Insurance Act include mandatory deductibles paid by patients; other (co) payments are not included. ${ }^{36}$ Indirect costs were not considered in this study, since no information on this aspect is available in the Vektis database.

\section{Utilisation and expenditures of type 2 diabetes-related complications}

We studied utilisation of and expenditures on specialised care for type 2 diabetes-related macrovascular and microvascular complications in more detail. We used DBCs indicating macrovascular and microvascular type 2 diabetes-related complications (online supplemental table 1) to assess both utilisation of and expenditures on specialised care.

Total expenditures on medical specialist care services were determined using the total reimbursed costs for this service type per study year, drawn from the APCD. However, in determining expenditures per type 2 diabetesrelated complication, a median Dutch price per DBC was calculated. This is because the prices for specific DBCs can differ to some extent between hospitals due to variations in contractual agreements made between individual hospitals and health insurers. ${ }^{37}$ Moreover, hospitals are known to raise or reduce the prices of specific DBCs for administrative purposes, for example, to meet a hospitalwide turnover constraint. As a consequence, DBC prices do not necessarily reflect the true cost of the correlated care episode. ${ }^{38}$ Thus, to mitigate the variation in expenditures introduced by administrative DBC pricing, we used the median Dutch price per DBC to calculate the expenditures on type 2 diabetes-related complications. For every 
Table 1 Characteristics of the Dutch type 2 diabetes population in 2016-2018

\begin{tabular}{|c|c|c|c|}
\hline & 2016 & 2017 & 2018 \\
\hline Annual prevalence, $\mathrm{n}$ & 880121 & 890682 & 900522 \\
\hline New patients, $\mathrm{n}$ & 58606 & 57877 & 57411 \\
\hline \multicolumn{4}{|l|}{ Loss to follow-up, $\mathrm{n}$} \\
\hline Deceased & 38042 & 38962 & 40050 \\
\hline Other reasons $^{\star}$ & 19055 & 9274 & 8609 \\
\hline Mean age, years (SD) & $67.4( \pm 12.4)$ & $68.5( \pm 12.4)$ & $68.7( \pm 12.3)$ \\
\hline Gender, female, n (\%) & $417912(47.5)$ & $419658(47.1)$ & $420988(46.7)$ \\
\hline \multicolumn{4}{|l|}{ Prevalence of chronic comorbidities, $n(\%) \dagger$} \\
\hline Heart disease & $111106(12.6)$ & $109892(12.3)$ & $109022(12.1)$ \\
\hline Depression & $51906(5.9)$ & $52427(5.9)$ & $51729(5.7)$ \\
\hline Thyroid disorders & $43879(5.0)$ & $43786(4.9)$ & $44612(5.0)$ \\
\hline Chronic obstructive pulmonary disease/severe asthma & $41162(4.7)$ & $41183(4.6)$ & $41383(4.6)$ \\
\hline Asthma & $39768(4.5)$ & $40611(4.6)$ & $41021(4.6)$ \\
\hline Glaucoma & $33364(3.8)$ & $33852(3.8)$ & $39200(4.4)$ \\
\hline Psychosis and addiction & $13841(1.6)$ & $14105(1.6)$ & $16929(1.9)$ \\
\hline Neuropathic pain & $10461(1.2)$ & $10945(1.2)$ & $11451(1.3)$ \\
\hline \multicolumn{4}{|l|}{ Prevalence of type 2 diabetes-related complications, $n$ (\%) } \\
\hline Macrovascular type 2 diabetes-related complications & $51684(5.9)$ & $51355(5.8)$ & $50825(5.6)$ \\
\hline Heart failure & $25835(2.9)$ & $25964(2.9)$ & $25627(2.8)$ \\
\hline Stroke & $17718(2.0)$ & $17449(2.0)$ & $17653(2.0)$ \\
\hline Acute coronary syndrome & $10712(1.2)$ & $10468(1.2)$ & $9932(1.1)$ \\
\hline Microvascular type 2 diabetes-related complications & $144877(16.5)$ & $144881(16.3)$ & $146216(16.2)$ \\
\hline Diabetic eye complications & $109332(12.4)$ & $108841(12.2)$ & $109859(12.2)$ \\
\hline Diabetic foot/peripheral angiopathy & $22724(2.6)$ & $22878(2.6)$ & $23221(2.6)$ \\
\hline Diabetic kidney disease & $22431(2.5)$ & $22736(2.6)$ & $22758(2.5)$ \\
\hline Diabetic mono/polyneuropathy & $1835(0.2)$ & $1754(0.2)$ & $1730(0.2)$ \\
\hline
\end{tabular}

*Other reasons for loss to follow-up may include people who no longer meet the inclusion criteria, people admitted to a nursing home and people who emigrated. Calculated as: (number of patients $y-1)+($ number of new patients $y)-($ number of deceased $y-1)-($ number of patients y).

†The FKGs present in over $1 \%$ of the type 2 diabetes population are displayed.

FKG, Farmaceutische KostenGroepen.

specific DBC, the median DBC price was determined by arranging all countrywide reimbursed DBCs of that type to find the median accordingly. As DBC prices vary over the years, this was done separately for each study year. Finally, to determine the total expenditures per type 2 diabetes-related complication, the associated reimbursed DBCs were multiplied by the related median DBC prices.

\section{Statistical analysis}

Data were analysed descriptively. The continuous variables age and per treated patient expenditures on type 2 diabetes-related complications were presented as means and SDs. For complications, the median expenditures per treated patient and the 5th and 95th percentile were also described. The categorical variables gender, presence of comorbidities, presence of type 2 diabetes-related complications and healthcare sector and service utilisation were reported as frequencies and valid percentages of the total type 2 diabetes population. Population and per patient expenditures on healthcare sectors and service types and type 2 diabetes-related complications were presented as frequencies and valid percentages. Due to the economic function of Vektis data, missing data are rare but in case of missing data the expenditures were imputed as zero, age was not imputed and gender was set to unknown.

The data were recovered and reported from the Vektis databases based on a detailed data extraction and processing request. The data were obtained and analysed using statistical package SAS V.7.15.

\section{Patient and public involvement}

This study aimed to gain an overview of healthcare utilisation of and expenditures on the Dutch type 2 diabetes population. Patients were not involved in the design, management or reporting of this study. 
Table 2 Share of the type 2 diabetes population with service use per healthcare sector and service type, 2016-2018

\begin{tabular}{|c|c|c|c|}
\hline & 2016 & 2017 & 2018 \\
\hline \multicolumn{4}{|l|}{ Healthcare sectors } \\
\hline Primary care, n (\%) & 879578 (99.9) & $890161(99.9)$ & 899998 (99.9) \\
\hline \multicolumn{4}{|l|}{ Healthcare service types } \\
\hline Pharmaceutical care, n (\%) & 871999 (99.1) & $882431(99.1)$ & 892250 (99.1) \\
\hline Assistive devices, n (\%) & 431867 (49.1) & 439249 (49.3) & 445438 (49.5) \\
\hline Paramedical care, n (\%) & 137206 (15.6) & $147129(16.5)$ & 161035 (17.9) \\
\hline District nursing, $\mathrm{n}(\%)$ & $130571(14.8)$ & $134209(15.1)$ & $141252(15.7)$ \\
\hline Mental healthcare, n (\%) & 42207 (4.8) & $42004(4.7)$ & $41989(4.7)$ \\
\hline
\end{tabular}

\section{RESULTS}

\section{Characteristics of the type 2 diabetes population}

In 2018,900522 people or $6.5 \%$ of the Dutch population aged 18 and above were identified as having type 2 diabetes (table 1). In total, 740353 patients received integrated diabetes care in that year. The type 2 diabetes population increased by $2.3 \%$ compared with 2016 ( $n=880$ 121). In 2018, the mean age of the Dutch type 2 diabetes population was $68.7( \pm 12.3)$ years and $46.7 \%$ of the population was woman. The most common chronic comorbidity (based on medication) was heart disease, with a prevalence of $12.1 \%$ in 2018 . This was followed by depression and thyroid disorders, with 2018-prevalences of $5.7 \%$ and $5.0 \%$, respectively. Moreover, based on specialised care utilisation, $5.6 \%$ of patients received care for macrovascular type 2 diabetes-related complications and $16.2 \%$ of patients received care for microvascular type 2 diabetesrelated complications. The most frequently occurring complications were diabetic eye complications: $12.2 \%$ of the type 2 diabetes population received specialised care for this. The second most common type 2 diabetesrelated complication identifiable through reimbursement was heart failure, as $2.8 \%$ of patients with type 2 diabetes received specialised care for this. The third most prevalent were care for diabetic foot/peripheral angiopathy and diabetic kidney disease (reimbursed for $2.6 \%$ and $2.5 \%$, respectively).

\section{Healthcare utilisation}

All patients with type 2 diabetes used care reimbursed under the Health Insurance Act in the timeframe 20162018. In 2018, 4.4\% of patients additionally used care reimbursed under the Long-term Care Act. Regarding services covered by the Health Insurance Act, table 2 shows that relatively large shares of the population used care in the specified healthcare sectors and service types. Almost all people with type 2 diabetes used pharmaceutical $(99.1 \%)$ and medical specialist care $(97.0 \%)$ in 2018. Moreover, the large majority of this population had GP consultations $(90.5 \%)$ and half of the type 2 diabetes population had reimbursements for the use of assistive devices. Mental healthcare was used by the smallest share of patients with type 2 diabetes (4.7\%). Reimbursements for paramedical care and district nursing increased most during the study period, by $17.4 \%$ and $8.2 \%$, respectively.

\section{Healthcare expenditures}

In figure 1, total healthcare expenditures of the Dutch type 2 diabetes population in 2018 are displayed. In total, $€ 8173$ million was reimbursed, an increase of $7.2 \%$ from 2016 (online supplemental figure 1). Of the total expenditures, $18.6 \%$ was on care under the Long-term Care Act, while the remaining $81.4 \%$ were expenditures reimbursed under the Health Insurance Act. As to the latter, medical specialist care accounted for the largest share of spending, that is, €3115 million or $38.1 \%$. District nursing accounted for the second largest share and increased by $12.0 \%$ from 2016 to $€ 1012$ million in 2018 . Expenditures on pharmaceutical care were $€ 942$ million, accounting for $11.5 \%$ of the total. The fourth largest share results from expenditures on primary care (including GP consultations), accounting for $6.0 \%$ of the total (€488 million).

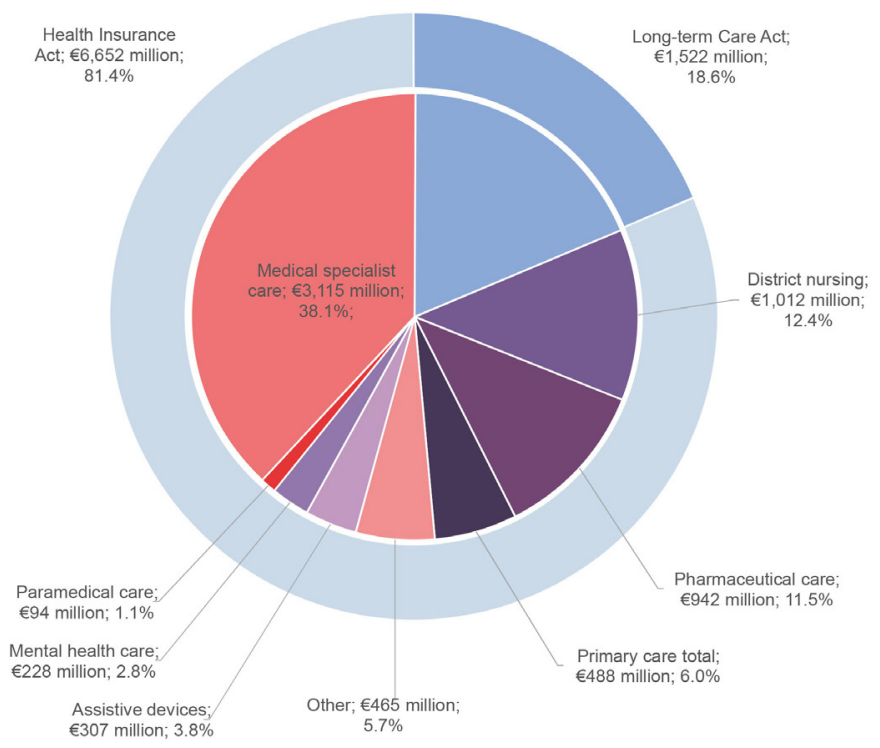

Figure 1 Total healthcare expenditures of the type 2 diabetes population in 2018. 


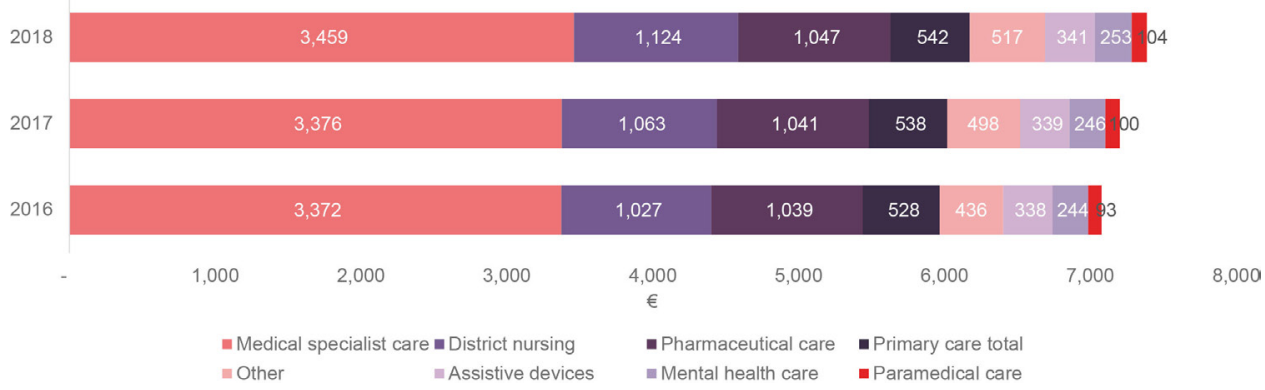

Figure 2 Mean annual per patient healthcare expenditures under the Health Insurance Act, 2016-2018.

\section{Mean annual per patient expenditures}

With regard to the Health Insurance Act, mean annual per patient spending increased by $4.4 \%$ from 2016 to 2018: $€ 7077$ to $€ 7386$ (figure 2 ). The annual spending on medical specialist care accounted for the largest share $(47 \%)$ or $€ 3459$ per patient in 2018. Second, district nursing and pharmaceutical care contributed to a significant share of annual per patient expenditures: $€ 1124$ and $€ 1047$, respectively. Moreover, the mean annual per patient expenditures on district nursing increased by 9.4\% from 2016 to 2018. Annual primary care expenditures were $€ 542$ per patient in 2018 . As to the category other, expenditures increased by $18.6 \%$ from 2016 and on average $€ 517$ was spent per patient in 2018. Per patient spending on assistive devices, mental healthcare and paramedical care were all under $5.0 \%$ of the total mean annual per patient expenditures. The patients with type 2 diabetes who received care under the Long-term Care Act as well as under the Health Insurance Act (4.4\%) had an average long-term care spending of $€ 38033$ in 2018. This increased by $14.4 \%$ in comparison to 2016 .

\section{Expenditures on type 2 diabetes-related complications}

In total, $€ 556$ million was spent on specialised care for type 2 diabetes-related complications in 2018 (table 3). The majority of these expenditures related to microvascular complications $(55.0 \%)$, which increased by $10.8 \%$ from 2016 to 2018. Spending on macrovascular complications increased by $2.1 \%$ during the same period. In 2018 , $€ 250$ million was spent on macrovascular type 2 diabetes-related complications. Diabetic foot/peripheral angiopathy accounted for the largest share of spending on diabetes-related complications with $20.9 \%$ or $€ 116$ million in 2018. Second, expenditures on strokes were $€ 111$ million in 2018. Third, total spending on diabetic eye complications increased by $11.2 \%$ over the studied period and accounted for $17.9 \%$ of the total in 2018. Moreover, for diabetic kidney disease, total expenditures increased by $12.8 \%$ from 2016 to 2018 (to $15.7 \%$ of the total). The per treated patient mean and median expenditures on type 2 diabetes-related complications were lowest for diabetic eye complications and diabetic mono/ polyneuropathy. The highest mean and median expenditures per treated patient were for stroke and acute coronary syndrome (online supplemental table 2 ).

\section{DISCUSSION}

This study is the first to use an APCD of the Dutch population to identify and characterise the type 2 diabetes population. Hereby, this study extends the knowledge of its characteristics and provides insight into healthcare utilisation and expenditures across healthcare sectors, service types and for type 2 diabetes-related complications. In 2018 , the annual prevalence of type 2 diabetes in the Netherlands was 900522 people (6.5\% of Dutch adults). The most prevalent comorbidity, based on medication use, was heart disease with a prevalence of $12.1 \%$. Moreover, $5.6 \%$ received specialised care for macrovascular and $16.2 \%$ of

Table 3 Total expenditures type 2 diabetes related complications 2016-2018 (million $€$ )

\begin{tabular}{|c|c|c|c|c|}
\hline & 2016 & 2017 & 2018 & Change in \% 2016-2018 \\
\hline Macrovascular type 2 diabetes-related complications, $\mathrm{n}(\%)$ & $245(47.0)$ & $249(46.7)$ & $250(45.0)$ & 2.1 \\
\hline Heart failure, $\mathrm{n}(\%)$ & $81(15.5)$ & $80(15.1)$ & $81(14.6)$ & 0.5 \\
\hline Stroke, n (\%) & $106(20.3)$ & $111(20.8)$ & $111(19.9)$ & 5.0 \\
\hline Acute coronary syndrome, $\mathrm{n}(\%)$ & $59(11.3)$ & $58(10.9)$ & $58(10.5)$ & -0.8 \\
\hline Microvascular type 2 diabetes-related complications, n (\%) & $276(53.0)$ & $284(53.3)$ & $306(55.0)$ & 10.8 \\
\hline Diabetic eye complications, n (\%) & $90(17.2)$ & $92(17.2)$ & $100(17.9)$ & 11.2 \\
\hline Diabetic foot/peripheral angiopathy, $\mathrm{n}(\%)$ & $106(20.4)$ & $110(20.7)$ & $116(20.9)$ & 9.7 \\
\hline Diabetic kidney disease, $\mathrm{n}(\%)$ & $78(14.9)$ & $79(14.9)$ & $88(15.7)$ & 12.8 \\
\hline Diabetic mono/polyneuropathy, n (\%) & $3(0.6)$ & $3(0.5)$ & $3(0.5)$ & -14.3 \\
\hline Total expenditures, n (\%) & $521(100.0)$ & $532(100.0)$ & $556(100.0)$ & 6.7 \\
\hline
\end{tabular}


the 2018 population received specialised care for microvascular complications. Regarding healthcare utilisation, almost all patients with type 2 diabetes used pharmaceutical care, medical specialist care and GP care. In total, $€ 8173$ million, about $9.4 \%$ of total healthcare expenditures, was reimbursed for the type 2 diabetes population in 2018. ${ }^{39}$ Expenditures on medical specialist care represented the largest share of total healthcare expenditures $(38.1 \%)$, followed by expenditures on district nursing (12.4\%) and pharmaceutical care $(11.5 \%)$.

The current study has a number of strengths. A major strength is the use of an APCD covering virtually all Dutch citizens, which ensures a heterogeneous cohort. Another advantage of an APCD is the accuracy of the data: to enable optimal risk equalisation among health insurers, data undergo extensive quality control before they are included in the Vektis databases. ${ }^{27}$ Quality control of the data used for risk equalisation is extremely important as Dutch health insurers have an obligation to accept all applicants and, as such, are highly dependent on a fair compensation for risk differences in order to survive in the market. ${ }^{33}$ The combination of a virtually complete data set, high data accuracy and completeness allowed us to estimate disease prevalence, resource utilisation and expenditures in a reliable manner. However, using all-payer claims data also presents drawbacks. Because of the nature of our data, we were only able to report direct medical costs and could not assess indirect medical costs. A recent Dutch study based on self-reported data, showed that indirect medical costs, such as productivity losses and informal care, accounted for $30 \%$ of total societal costs for patients with type 2 diabetes. ${ }^{12}$ As $70 \%$ is related to direct medical costs, we did assess the majority of expenditures in this study. In addition, despite the heterogeneous cohort, the generalisability of certain findings may be limited on an international level due to differences in the organisation of healthcare. For instance, the number and duration of hospitalisations and expenditures on pharmaceutical care are found to vary between established markets. ${ }^{40-42}$ Additionally, for claims data, real-time or near-time data use, for example, for research findings to apply in policy and practice and vice versa is hampered by the 2-year time lag in data. Moreover, the Dutch claims data do not include specific diagnostic codes for type 2 diabetes. Therefore, we determined the type 2 diabetes population with a number of inclusion criteria. However, a small share of patients with type 2 diabetes cannot be identified through claims data, that is, patients who do not receive integrated diabetes care and do not use any diabetes medication or use insulin only, and patients with type 2 diabetes who live in nursing homes and receive all care within the facility. Nevertheless, the effect of not detecting these patients is likely to be minimal, as the large majority of patients with type 2 diabetes receive integrated diabetes care $(83 \%)$ and if not, many are included due to medication use for type 2 diabetes $(80 \%$ received diabetes medication in 2018) ${ }^{28}{ }^{43}$ Similarly, we found that with our first inclusion criterion ('received integrated diabetes care') we identified 740353 patients with type 2 diabetes, that is, $82.2 \%$ of the total number of patients identified in 2018. Thus, the size of our identified population matches existing estimates on the number of patients with type 2 diabetes mellitus treated in integrated primary care. Moreover, as we used claims data, we were only able to identify chronic comorbidities and type 2 diabetes-related complications for which patients recently used care, which could lead to an underestimation of the prevalences of these conditions. However, we believe this underestimation is limited in scope, as prior research has shown that the presence of comorbidities and complications in diabetes strongly predicts a higher volume of medical healthcare utilisation. ${ }^{7-12}$

Notwithstanding these limitations, our APCD enables a detailed and complete overview of the type 2 diabetes population. However, our findings regarding population size differ from the type 2 diabetes population as estimated by NIVEL (Netherlands Institute for Health Services Research). ${ }^{44}$ Their findings indicated an annual prevalence of 1079624 people with type 2 diabetes in 2018. ${ }^{6}$ However, this estimate is based on GP registration data representing approximately $10 \%$ of the Dutch population, ${ }^{44}$ whereas we included data on the total Dutch population. Also, morbidity estimates of GPs may be less reliable as these are potentially influenced by the local organisation of the healthcare system, methods of morbidity registration, the organisation of the GP practice and patient characteristics. ${ }^{45}$ Lastly, once a patients with type 2 diabetes is included in the NIVEL cohort, they do leave the cohort for reasons other than mortality. Hence, their approach potentially results in an overestimation of the actual prevalence of type 2 diabetes.

Notably, our findings indicated that the majority of healthcare utilisation and expenditures of the type 2 diabetes population are not directly related to diabetes. Patients with type 2 diabetes use care throughout the healthcare system, that is, across healthcare sectors and service types. Additionally, $97.0 \%$ of patients with type 2 diabetes use medical specialist care despite $83 \%$ receiving integrated diabetes care in the primary care setting. ${ }^{28}$ Moreover, medical specialist care utilisation of the type 2 diabetes population is considerably higher than the share of the entire insured population in the Netherlands that uses medical specialist care ( $43 \%$ in 2017). ${ }^{46}$ The wide dispersion of service use across the health system, as well as the high utilisation of medical specialist care, may be explained by the presence of comorbidities and complications. Many patients not only have type 2 diabetes but additionally suffer from other conditions, as is confirmed in this study as well as shown in previous literature. ${ }^{78}$ Findings that comorbidities substantially increase healthcare expenditures and utilisation are also in line with previous studies on this topic. ${ }^{7-12}$

The high utilisation of non-diabetes care of the type 2 diabetes population has several implications for policymakers. As a large share of healthcare utilisation and expenditures is caused by comorbidities or type 2 
diabetes-related complications, it could be beneficial to organise care more holistically and approach diabetes and non-diabetes reports more concentrated in the health system. Such an approach would underpin the need to shift from a disease-specific approach to a person-centred and integrated care approach. This is in agreement with prior findings indicating that person-centred integrated care may be meaningful in making the care process less fragmented and improving physical and psychological health in patients with multimorbidity. ${ }^{48}$ Additionally, the high utilisation of and expenditures across the healthcare system show that diabetes care is not necessarily expensive but the total care for patients known with type 2 diabetes is. Therefore, when addressing healthcare expenditures, policymakers should not only focus on utilisation of and expenditures on diabetes care but also on care for concurrent morbidities and complications. Prior research has also shown that integrated care adapted to the needs of chronically ill patients could lead to better outcomes at lower costs. ${ }^{49}$

Therefore, future research exploring the characteristics of high-need (utilisation) and high-cost (expenditures) subgroups within the type 2 diabetes population may provide new insights into relevant trigger factors for high care consumption. Such insights can inform initiatives to reduce spending growth and thereby maintain the financial sustainability of healthcare systems. We identified a high level of dispersion in care use, combined with a large share of patients with type 2 diabetes that use specialised care. These findings illustrate the need to further delineate specific type 2 diabetes subgroups with similar resource use, and better understand their courses of disease, background characteristics and exposure to risk factors, to enable evidence-based tailoring and improvement of care. Moreover, APCDs can be used for longitudinal retrospective analyses, for instance to show long-term effects of policies or treatment changes to determine whether these were effective and support sustainability. Additionally, future research should focus further on the dispersion of healthcare utilisation of and expenditures on the type 2 diabetes population. Insight into pharmaceutical care and medical specialist care utilisation would be particularly meaningful as these healthcare services are heavily used by this population. Moreover, to better understand the impact of type 2 diabetes on healthcare utilisation and healthcare expenditures, future research should compare people with and without type 2 diabetes.

\section{CONCLUSIONS}

APCDs can be used to identify the national type 2 diabetes population and describe its characteristics, healthcare utilisation and healthcare expenditures. This insight can inform policymakers and practice about dispersion of reimbursed care, directly and indirectly related to type 2 diabetes, and in turn support better decisions to promote long-term (financial) sustainability of healthcare systems.

\section{Author affiliations}

${ }^{1}$ Department of Health Services Research, CAPHRI Care and Public Health Research Institute, Faculty of Health, Medicine and Life Sciences, Maastricht University,

Maastricht, The Netherlands

${ }^{2}$ Department of Internal Medicine, University Medical Centre Groningen, Groningen, The Netherlands

${ }^{3}$ Department of Quality of Care and Health Economics, Center for Nutrition, Prevention and Health Services, National Institute of Public Health and the Environment (RIVM), Bilthoven, The Netherlands

${ }^{4}$ Department Public Health and Primary Care, Leiden University Medical Center Campus The Hague, The Hague, The Netherlands

${ }^{5}$ Department Intelligence, Vektis Healthcare Information Center, Zeist, The Netherlands

Twitter Arianne M J Elissen @ArianneElissen

Acknowledgements We thank Michiel ten Hove, Robin Stoof and Paul Sterkenburg of Vektis for their assistance on developing the study design and for answering our questions about the data.

Contributors RJG, AMJE, JNS and DR were involved in the design of the study. A detailed data extraction and processing request for data acquisition was made by RJG, AMJE and HJGB and approved by DR and JNS. CvT performed data acquisition and assisted data analysis. All authors were involved in checking the accuracy and completeness of the data. RJG conducted data analysis, drafting and manuscript writing. AMJE, HJGB, JNS and DR all critically reviewed and revised the drafts and contributed to writing. All authors approved the final version and were involved in the decision to submit it for publication. RJG is the guarantor of this work and takes responsibility for the integrity of the data and the accuracy of the data analysis.

Funding The current study was funded by AstraZeneca Netherlands. The study sponsor was not involved in the design of the study; the collection, analysis and interpretation of data; writing the report; and did not impose any restrictions regarding the publication of the report.

Competing interests None declared.

Patient consent for publication Not applicable.

Ethics approval According to the Maastricht University Medical Center ethics committee, this study is not subject to the Dutch 'Research involving Human Subjects act' (registration number 2019-1445).

Provenance and peer review Not commissioned; externally peer reviewed.

Data availability statement Data may be obtained from a third party and are not publicly available. The data sets generated and analysed during this study are not publicly available, as formal consent from the Dutch health insurers is needed to gain access to these files. Data are however available from Vektis upon reasonable request and with formal consent of the Dutch health insurers.

Supplemental material This content has been supplied by the author(s). It has not been vetted by BMJ Publishing Group Limited (BMJ) and may not have been peer-reviewed. Any opinions or recommendations discussed are solely those of the author(s) and are not endorsed by BMJ. BMJ disclaims all liability and responsibility arising from any reliance placed on the content. Where the content includes any translated material, BMJ does not warrant the accuracy and reliability of the translations (including but not limited to local regulations, clinical guidelines, terminology, drug names and drug dosages), and is not responsible for any error and/or omissions arising from translation and adaptation or otherwise.

Open access This is an open access article distributed in accordance with the Creative Commons Attribution Non Commercial (CC BY-NC 4.0) license, which permits others to distribute, remix, adapt, build upon this work non-commercially, and license their derivative works on different terms, provided the original work is properly cited, appropriate credit is given, any changes made indicated, and the use is non-commercial. See: http://creativecommons.org/licenses/by-nc/4.0/.

ORCID iDs

Rose J Geurten http://orcid.org/0000-0002-4638-8114

Arianne M J Elissen http://orcid.org/0000-0001-9795-8095

\section{REFERENCES}

1 Maarse H, Jeurissen P, Ruwaard D. Concerns over the financial sustainability of the Dutch healthcare system. DICE Rep 2013;11:32-6. 
2 Liaropoulos L, Goranitis I. Health care financing and the sustainability of health systems. Int J Equity Health 2015;14:5-8.

3 Birch S, Murphy GT, MacKenzie A, et al. In place of fear: aligning health care planning with system objectives to achieve financial sustainability. J Health Serv Res Policy 2015;20:109-14.

4 WHO. Programmes and projects - Nutrition - Nutrition health topics - 5. Population nutrient intake goals for preventing diet-related chronic diseases. Available: https://www.who.int/nutrition/topics/5 population_nutrient/en/ [Accessed 13 Nov 2019].

5 Williams R, Colagiuri S, Almutairi R. IDF diabetes atlas. 9th edn Brussels, BE: International Diabetes Federation, 2019: 36-9.

6 Rijksinstituut voor Volksgezondheid en Milieu (RIVM). Diabetes mellitus - Cijfers \& Context - Huidige situatie. [The National Institute of Public Health and the Environment on Diabetes Mellitus Numbers and Context: The current situation]. Available: https://www. volksgezondheidenzorg.info/onderwerp/diabetes-mellitus/cijferscontext/huidige-situatie\#node-aandeel-diabetes-type-1-totaal-naarleeftijd-en-geslacht [Accessed 28 Oct 2018]

7 Williams R, Van Gaal L, Lucioni C. Assessing the impact of complications on the costs of type II diabetes. Diabetologia 2002;45:S13-17.

8 Struijs JN, Baan CA, Schellevis FG, et al. Comorbidity in patients with diabetes mellitus: impact on medical health care utilization. BMC Health Serv Res 2006;6:1-9.

9 Tamayo T, Rosenbauer J, Wild SH, et al. Diabetes in Europe: an update. Diabetes Res Clin Pract 2014;103:206-17.

10 Hazel-Fernandez L, Li Y, Nero D, et al. Relationship of diabetes complications severity to healthcare utilization and costs among Medicare advantage beneficiaries. Am J Manag Care 2015;21:e62-70.

11 Kanavos P, Den ASV, Schurer W. Diabetes expenditure, burden of disease and management in 5 EU countries. LSE heal London Sch Econ, 2012. Available: http://eprints.Ise.ac.uk/54896/1/ libfile REPOSITORY_Content_LSE Health and Social Care_Jan 2012_LSED iabetesReport26Jan2012.pdf [Accessed 30 Oct 2019].

12 Janssen LMM, Hiligsmann M, Elissen AMJ, et al. Burden of disease of type 2 diabetes mellitus: cost of illness and quality of life estimated using the Maastricht study. Diabet Med 2020;37:1-7.

13 Ogurtsova K, da Rocha Fernandes JD, Huang Y, et al. IDF diabetes atlas: global estimates for the prevalence of diabetes for 2015 and 2040. Diabetes Res Clin Pract 2017:128:40-50.

14 Pagano E, De Rosa M, Rossi E, et al. The relative burden of diabetes complications on healthcare costs: the population-based CINECASID ARNO diabetes observatory. Nutr Metab Cardiovasc Dis 2016;26:944-50.

15 Li R, Bilik D, Brown MB, et al. Medical costs associated with type 2 diabetes complications and comorbidities. Am J Manag Care 2013;19:421-30.

16 Zgibor JC, Orchard TJ, Saul M, et al. Developing and validating a diabetes database in a large health system. Diabetes Res Clin Pract 2007;75:313-9.

17 de Groot S, Enters-Weijnen CF, Geelhoed-Duijvestijn PH, et al. A cost of illness study of hypoglycaemic events in insulin-treated diabetes in the Netherlands. BMJ Open 2018;8:e019864.

18 Nichols GA, Desai J, Elston Lafata J, et al. Construction of a multisite Datalink using electronic health records for the identification, surveillance, prevention, and management of diabetes mellitus: the SUPREME-DM project. Prev Chronic Dis 2012;9:1-9.

19 Slabaugh SL, Curtis BH, Clore G, et al. Factors associated with increased healthcare costs in Medicare advantage patients with type 2 diabetes enrolled in a large representative health insurance plan in the US. J Med Econ 2015;18:106-12.

20 Charbonnel B, Simon D, Dallongeville J, et al. Direct medical costs of type 2 diabetes in France: an insurance claims database analysis. Pharmacoecon Open 2018;2:209-19.

21 Jacobs E, Hoyer A, Brinks R, et al. Healthcare costs of type 2 diabetes in Germany. Diabet Med 2017;34:855-61.

22 van Schoonhoven AV, Gout-Zwart JJ, de Vries MJS, et al. Costs of clinical events in type 2 diabetes mellitus patients in the Netherlands: a systematic review. PLoS One 2019;14:e0221856.

23 Jo C. Cost-of-illness studies: concepts, scopes, and methods. Clin Mol Hepatol 2014;20:327-37.

24 Freedman JD, Green L, Landon BE. All-payer claims databases - uses and expanded prospects after Gobeille. N Engl J Med 2016;375:2215-7.

25 Love D, Custer W, Miller P. All-payer claims databases: state initiatives to improve health care transparency. Issue Brief 2010;99:1-14.

26 Dworsky M. Using all-payer claims databases to study insurance and health care utilization dynamics. J Gen Intern Med 2017;32:1069-70.
27 Hrzic R, Clemens T, Westra D, et al. Comparability in cross-national health research using insurance claims data: the cases of Germany and the Netherlands. Gesundheitswesen 2020;82:S83-90.

28 Klomp M, Romeijnders A, de Braal E InEen - Transparante Ketenzorg Rapportage 2019 Zorggroepen: diabetes mellitus, VRM COPD en Astma. Spiegel voor het verbeteren van chronische zorg. p.13-20. [Report on Transparency in Integrated Diabetes Care and Care Groups], 2019. Available: https://ineen.nl/wp-content/uploads/ 2020/07/200715-Benchmark-Transparante-ketenzorg-2019-web.pdf [Accessed 30 Sep 2020].

29 Struijs JN, Baan CA. Integrating care through bundled payments-lessons from the Netherlands. N Engl J Med 2011;364:990-1.

30 Sluiter AC, Van Wijland JJ, Arntzenius A. Landelijke Transmurale Afspraak Diabetes mellitus type 2 [National Transmural Agreement Type 2 diabetes mellitus]. Huisarts Wet 2012;55:S1-12.

31 Barents ESE, Bilo HJG, Bouma M. NHG standaard - Diabetes mellitus type 2 - Richtlijnen beleid - Medicamenteuze therapie [Medication guidelines for type 2 diabetes Melitus type]. Available: https://richtlijnen.nhg.org/standaarden/diabetes-mellitus-type-2 [Accessed 19 Jul 2021].

32 Overheid. Besluit zorgverzekering - Hoofdstuk 1. Definities en algemene bepalingen - Artikel 1. [Decisions on health insurance Chapter 1. Definitions and general provisions - Article 1]. Available: https://wetten.overheid.nl/BWBR0018492/2021-01-01 [Accessed 13 Mar 2020].

33 Van Kleef RC, Van Vliet RCJA, Van de Ven WPMM. Risk equalization in the Netherlands: an empirical evaluation. Expert Rev Pharmacoecon Outcomes Res 2013;13:829-39.

34 Elissen A, Duimel-Peeters I, Spreeuwenberg C. Assessing chronic disease management in European health systems country reports. Copenhagen, DK: WHO Regional Office for Europe, 2015: 99-110.

35 Nathanson D, Sabale U, Eriksson JW, et al. Healthcare cost development in a type 2 diabetes patient population on glucoselowering drug treatment: a nationwide observational study 20062014. Pharmacoecon Open 2018;2:393-402.

36 Vektis. Bijsluiter: Vektis Open Databestanden Zorgverzeketingswet 2011-2018 [Information leaflet of open-access Health-Insurance Act Vektis databases]. Available: https://www.vektis.nl/uploads/ Docs\%20per\%20pagina/Open\%20Data\%20Bestanden/Bijsluiter\% 20bij\%20de\%20Vektis\%20Open\%20Databestanden\%20Zorgve rzekeringswet\%202011\%20-\%202018\%20.pdf [Accessed 12 Nov 2020].

37 Berden C, Croes R, Kemp R. Hospital competition in the Netherlands: an empirical investigation. Discuss Pap [online], 2019. Available: https://pure.uvt.nl/ws/portalfiles/portal/30034784/DP2019_ 008.pdf [Accessed 12 Nov 2020].

38 Nederlandse Zorgautoriteit (NZa). Advies bekostiging medischspecialistische zorg, Belonen van zorg die waarde toevoegt [Presentation of The Dutch Healthcare Authority regarding advice on medical specialist care reimbursement]. Available: https://www. rijksoverheid.nl/documenten/rapporten/2018/10/04/belonen-vanzorg-die-waarde-toevoegt [Accessed 12 Nov 2020].

39 CBS. StatLine - Zorguitgaven in drie benaderingen; zorgaanbieders [Care expenditures approached in three ways; care providers]. Available: https://opendata.cbs.nl/\#/CBS/nl/dataset/84054NED/ table?dl=3AB46\&ts=1605793224356 [Accessed 19 Nov 2020].

40 Alzaid A, Ladrón de Guevara P, Beillat M, et al. Burden of disease and costs associated with type 2 diabetes in emerging and established markets: systematic review analyses. Expert Rev Pharmacoecon Outcomes Res 2021:21:1-14.

41 Müller N, Heller T, Freitag MH, et al. Healthcare utilization of people with type 2 diabetes in Germany: an analysis based on health insurance data. Diabet Med 2015;32:951-7.

42 Jönsson B. Revealing the cost of type II diabetes in Europe. Diabetologia2002;45:S5-12.

43 Stichting Farmaceutische Kerngetallen. Data en feiten 2019 - Het jaar 2018 in cijfers [The Foundation of Pharmaceutical Key figures on data and facts - the year 2018 in numbers][online article], 2019. Available: https://www.sfk.nl/publicaties/data-en-feiten/data-enfeiten-2019 [Accessed 29 Sep 2020].

44 Nivel. Volksgezondheidenzorg.info - NIVEL Zorgregistraties eerste lijn - Algemeen [The Dutch Institute for Health Services Research - care records in primary care]. Available: https://bronnen.zorggegevens. $\mathrm{nl} /$ Bron?naam=Nivel-Zorgregistraties-eerste-lijn [Accessed 30 Oct 2020].

45 van den Dungen C, Hoeymans N, Gijsen R, et al. What factors explain the differences in morbidity estimations among general practice registration networks in the Netherlands? a first analysis. Eur $J$ Gen Pract 2008;14:53-62.

46 Vektis. Inzichten in medisch-specialistische zorg [insights into medical specialist care]. Available: https://www.zorgprismapubliek.nl/ 
producten/ziekenhuiszorg/medisch-specialistische-zorg/ [Accessed 30 Sep 2020].

47 Inzucchi SE, Bergenstal RM, Buse JB. Management of hyperglycemia in type 2 diabetes: a patient-centered approach. Diabetes Care 2012;35:1364-79.

48 Berntsen G, Høyem A, Lettrem I, et al. A person-centered integrated care quality framework, based on a qualitative study of patients' evaluation of care in light of chronic care ideals. BMC Health Serv Res 2018:18:1-15.

49 Mitri J, Gabbay R. Understanding population health through diabetes population management. Endocrinol Metab Clin North Am 2016;45:933-42. 